\title{
Remerciements
}

\section{Claire Dubus}

\section{OpenEdition}

Journals

Édition électronique

URL : https://journals.openedition.org/eastafrica/552

DOI : 10.4000/eastafrica.552

ISSN : 2790-1076

Éditeur

IFRA - Institut Français de Recherche en Afrique

Édition imprimée

Date de publication : 1 avril 2010

Pagination : viii

ISSN : 2071-7245

\section{Référence électronique}

Claire Dubus, «Remerciements », Les Cahiers d'Afrique de l'Est / The East African Review [En ligne], 43 | 2010, mis en ligne le 19 juillet 2019, consulté le 09 décembre 2021. URL : http://

journals.openedition.org/eastafrica/552 ; DOI : https://doi.org/10.4000/eastafrica.552

Ce document a été généré automatiquement le 9 décembre 2021.

Les Cahiers d'Afrique de l'Est / The East African Review 


\title{
Remerciements
}

\author{
Claire Dubus
}

1 Je remercie ici Philippe Gervais-Lambony et Myriam Houssay-Holzschuch, qui m'ont dirigée pendant la rédaction de ce mémoire, et qui m’ont apporté des conseils précieux, des remarques judicieuses et des questionnements vraiment stimulants.

2 Mes remerciements vont aussi à Bernard Calas, dont la connaissance de la société tanzanienne et l'intérêt amical pour mon travail m'ont aidée à conduire mes recherches.

3 Mais c'est surtout les gens que j'ai rencontrés sur place, qui m'ont consacré du temps avec ouverture, courtoisie et gentillesse, que je voudrais remercier : Gérard Bruno et sa famille ; James Lindi, FID Q, Saigon qui ont bien voulu me recevoir ; Fratelin Kashiaga, grâce à qui j'ai pu consulter les fonds de la bibliothèque universitaire, ce qui était loin d'être évident... ; Walter Bgoya et son épouse, qui m'ont chaleureusement accueillie, et fait part de leur longue expérience de la vie culturelle de Dar ; Tim Curtis, dont l'amitié m'est encore plus précieuse que son expérience passionnante d'anthropologue et son travail à l'Unesco; $\mathrm{M}$. Wills, qui a eu la gentillesse de mettre à ma disposition un bureau à l'ambassade de France lors de mon passage en février 2007 - non négligeable, lorsque le mois de février fait de Dar une fournaise humide ; et Theodatia, dada yangu, ma sœur de Tanzanie.

4 Un « special BIG UP » à Dola, installé à New York et jamais rencontré, mais dont l'aide, les conseils, et les points de vue m'ont été plus qu'utiles : un vrai « ami » myspacien...

5 Pour les sourires, enfin. Malgré la chaleur, les incompréhensions, les frimeurs, les dragueurs, les arrogants-bedonnants, les furies jalouses, les dala-dala qui explosent, les illuminés, la misère si quotidienne qu'elle en devient invisible de banalité... on danse souvent, on boit - beaucoup, on chante - tout le temps, et on sourit - toujours.

Ninashukuru sana. 